\title{
Sex Differences in the Prevalence and Modulators of Sleep-Disordered Breathing in Outpatients with Type 2 Diabetes
}

\author{
T. Kroner, ${ }^{1}$ M. Arzt, ${ }^{1}$ M. Rheinberger, ${ }^{2}$ M. Gorski, ${ }^{3}$ I. M. Heid, ${ }^{3}$ C. A. Böger, ${ }^{2}$ and S. Stadler $\mathbb{D}^{1}$ \\ ${ }^{1}$ Department of Internal Medicine II, University Hospital Regensburg, Franz-Josef-Strauss-Allee 11, 93053 Regensburg, Germany \\ ${ }^{2}$ Department of Nephrology, University Hospital Regensburg, Franz-Josef-Strauss-Allee 11, 93053 Regensburg, Germany \\ ${ }^{3}$ Department of Genetic Epidemiology, University of Regensburg, Franz-Josef-Strauss-Allee 11, 93053 Regensburg, Germany
}

Correspondence should be addressed to S. Stadler; stefan.stadler@ukr.de

Received 15 December 2017; Revised 11 February 2018; Accepted 13 February 2018; Published 1 April 2018

Academic Editor: Raffaele Marfella

Copyright (c) 2018 T. Kroner et al. This is an open access article distributed under the Creative Commons Attribution License, which permits unrestricted use, distribution, and reproduction in any medium, provided the original work is properly cited.

In patients with type 2 diabetes, sleep-disordered breathing is a widespread cause of deteriorated quality of life. However, robust prevalence estimates for sleep-disordered breathing in patients with type 2 diabetes are limited due to scarce data. We investigated sex differences in sleep-disordered breathing prevalence and its modulators in the DIACORE SDB substudy, a sample of outpatient type 2 diabetes. 721 participants were tested for sleep-disordered breathing using a two-channel sleep apnoea monitoring device. Patients were stratified according to the severity of sleep-disordered breathing, defined as an apnoeahypopnoea index $<15, \geq 15$ to 29 , and $\geq 30$ events per hour as no/mild, moderate, and severe sleep-disordered breathing, respectively. In the 679 analysed patients (39\% women, age $66 \pm 9$ years, body mass index $31.0 \pm 5.4 \mathrm{~kg} / \mathrm{m}^{2}$ ), the prevalence of sleep-disordered breathing was $34 \%$. The prevalence of sleep-disordered breathing was higher in men than in women $(41 \%$ versus $22 \%, p<0.001)$ and increased with age $(15 \%, 21 \%$, and $30 \%$ in women and $35 \%, 40 \%$, and $47 \%$ in men in those aged $18-59,60-69$, or $\geq 70$, respectively; age trend $p=0.064$ in women and $p=0.15$ in men). In linear regression analysis, age, BMI, and waist-hip ratio were associated with apnoea-hypopnoea index. Modulators for higher apnoea-hypopnoea index seem to be similar in men and women.

\section{Introduction}

The International Diabetes Federation reports a worldwide prevalence of diabetes mellitus of $8.8 \%$, where type 2 diabetes (T2D) makes up $87-91 \%$ in high-income countries and is more common in men than in women [1]. Because of the aging population and the increasing number of obese people, the prevalence of T2D has become more than doubled during the last three decades [2]. T2D may lead to several late diabetic comorbidities like neuropathy, nephropathy, and arteriosclerosis.

Sleep-disordered breathing (SDB), which is classified into obstructive and central sleep apnoea, is characterised by repetitive apnoeas and hypopnoeas, arousals from sleep as well as alterations of heart rate, and elevated blood pressure $[3,4]$. Using an apnoea-hypopnoea index (AHI) cut-off of $\geq 15 / \mathrm{h}$, the prevalence of SDB ranges from 7 to $14 \%$ in men and 2 to $7 \%$ in women, with increases over the last two decades $[5,6]$.

It is well documented that treatment with positive airway pressure effectively suppresses obstructive sleep apnoea, reduces sleep fragmentation, and restores normal sleep structure in patients with cardiac disease [7, 8]. It leads to significant improvement of daytime sleepiness and quality of life, even in patients reporting only mild SDB-related symptoms [9]. Previous studies investigated the association between SDB and T2D. When focusing on moderate to severe forms of SDB $(\mathrm{AHI} \geq 15 / \mathrm{h})$ with an indication for treatment [4], 24 to $53 \%$ of patients with T2D suffer from SDB [10-12], compared to $16 \%$ without T2D [10].

However, previous studies provide only limited information about the prevalence and its modulators for SDB in women with diabetes. Even if there was a nearly balanced ratio in the number of men and women in most studies, they 
used smaller sample sizes [10-12] or included only selected patients such as obese [12] or hospitalized patients [13]. Both T2D and SDB are common in men and women, but often underdiagnosed in women $[14,15]$. We analysed a sample of patients with T2D with an equal number of men and women $(61 \% / n=412$ men and $39 \% / n=267$ women $)$ and investigated sex differences in the prevalence of SDB as well as modulators that were associated with SDB.

\section{Material and Methods}

2.1. Study Design. The investigated patients were participants of the DIACORE (DIAbetes COhoRtE) SDB substudy [16]. DIACORE is designed as a two-center, prospectively planned study of T2D patients of European descent, with a baseline survey conducted in 2010-2014 and recruitment and ascertainment described previously [16, 17]. Briefly, written invitations were mailed to all T2D patients registered with five medical insurance companies in the respective year of the mailing and to all T2D outpatients of two diabetologists in Regensburg that had visited the offices within the last 6 months of the mailing. Further, invitations were sent to T2D patients who had received inpatient treatment at the University Hospital Regensburg's Internal Medicine Departments within two years prior to the mailing. Overall, 4226 patients contacted DIACORE, of which 1226 did not fulfil the inclusion and exclusion criteria. Diabetes status was ascertained by assessing diabetes medication or by validating self-report. Patients were subjected to a standardized online questionnaire, blood sampling, and physical examination at the two study centers.

Of 1036 individuals invited to participate in the DIACORE SDB substudy, 721 individuals with T2D from the region around Regensburg, Germany, agreed to participate and were tested with a two-channel ambulatory SDB monitoring device (ApneaLink ${ }^{\circledR}$, ResMed). In 679 patients (94\% of the 721 tested), complete SDB parameters were recorded. Apparative monitoring for SDB was not performed in the Mannheim study center. A two-year follow-up is currently ongoing [17]; for this investigation, the cross-sectional baseline dataset was used. The protocol, data protection strategy, and study procedures were approved by the ethics committees of both participating institutions and are in accordance with the Declaration of Helsinki. Patients participated in DIACORE only after providing informed written consent.

2.2. Study Population. All T2D outpatients inhabiting the city and county of Regensburg or Speyer were eligible for DIACORE. Further inclusion criteria were the ability to fully understand the study information and to provide written informed consent, age $\geq 18$ years, and self-reported Caucasian ethnicity. Exclusion criteria were chronic renal replacement therapy (haemodialysis, peritoneal dialysis, or transplantation), history of active malignancy within the last five years, autoimmune-disease potentially affecting kidney function, hemochromatosis, known pancreoprivic or self-reported type 1 diabetes, acute infection, fever, pregnancy, and chronic viral hepatitis or HIV-infection. For the DIACORE SDB substudy, patients were included if they consented to perform SDB monitoring and excluded if they currently use positive airway pressure therapy.

2.3. Assessment of $S D B$. Nasal flow and pulse oximetry were measured using the ApneaLink device (ResMed, Sydney, Australia), which has been validated in several studies for testing of SDB as described previously $[18,19]$ and is easy to mount at home by the patient himself. Trained study personnel instructed participants in the use of the device in a standardized fashion. Comparing ApneaLink to the gold standard polysomnography, studies have reported a sensitivity of $73-94 \%$ and a specificity of $85-95 \%$ using an AHI cut-off value of $15 / \mathrm{h}[19,20]$. AHI, oxygen desaturation index (ODI), mean oxygen saturation $\left(\mathrm{SpO}_{2}\right)$, and minimum $\mathrm{SpO}_{2}$ were documented. The default settings of the monitoring device were used for the definitions of apnoea, hypopnoea, and desaturation: apnoea was defined as a $\geq 80 \%$ decrease in airflow for $\geq 10$ seconds; hypopnoea was defined as a decrease in airflow by $50-80 \%$ versus baseline for $\geq 10$ seconds followed by $\mathrm{a} \geq 4 \%$ decrease in oxygen saturation.

No or mild SDB was defined as AHI $<15 / \mathrm{h}$, moderate SDB as AHI $\geq 15 / \mathrm{h}$ to $29 / \mathrm{h}$, and severe SDB was defined as $\mathrm{AHI} \geq 30 / \mathrm{h}$. Periodic breathing (Cheyne-Stokes respiration) was detected by automatic pattern recognition [21]. Due to the lack of a chest band, a clear differentiation between types of SDB, such as obstructive and central apnoea, was not possible.

Additionally, subjective daytime sleepiness was assessed using the self-administered validated Epworth Sleepiness Scale (ESS). Individuals were asked to rate their likelihood of falling asleep in several common situations. Scores range from 0 (least sleepy) to 24 (sleepiest). Excessive daytime sleepiness is defined as a score of 11 or higher [22].

2.4. Statistical Analysis. Descriptive data are presented as absolute and relative numbers or as mean \pm standard deviation (SD). Normally distributed values of baseline characteristics were evaluated with analysis of variance (ANOVA). Differences in AHI between age groups were tested with ANOVA and followed by pair-wise $t$-tests (Bonferroni corrected level of significance); sex differences in AHI were tested with $t$-tests.

Linear regression models were used for continuous variables and logistic regression for categorical variables, in order to investigate the association between different clinical variables. Sex, age, body mass index (BMI), waist-hip ratio, systolic blood pressure, and duration of T2D were included as covariates in these models. Variables included in the linear regression models were either normally distributed or transformed prior to incorporation in the models. Results are given as regression coefficient $B$ in linear models and as odds ratio OR in logistic regression models with $95 \%$ confidence interval (CI); $p$ values less than 0.05 were considered statistically significant. Data were analysed using the SPSS statistical software package (SPSS 20.0, IBM SPSS Statistics, Armonk, New York, USA). 
TABLE 1: Clinical characteristics of the 679 analysed subjects of the DIACORE baseline visit.

\begin{tabular}{|c|c|c|c|}
\hline Characteristic & Women $(n=267)$ & $\operatorname{Men}(n=412)$ & All $(n=679)$ \\
\hline Age [years] & $65 \pm 10$ & $66 \pm 8$ & $66 \pm 9$ \\
\hline BMI $\left[\mathrm{kg} / \mathrm{m}^{2}\right]$ & $31.9 \pm 6.0$ & $30.3 \pm 4.8$ & $31.0 \pm 5.4$ \\
\hline Waist-hip ratio & $0.9 \pm 0.07$ & $1.00 \pm 0.06$ & $0.96 \pm 0.08$ \\
\hline Waist circumference $[\mathrm{cm}]$ & $98 \pm 14$ & $102 \pm 18$ & $101 \pm 17$ \\
\hline Triglycerides $[\mathrm{mg} / \mathrm{dl}]$ & $163 \pm 80$ & $177 \pm 156$ & $171 \pm 131$ \\
\hline HDL-C [mg/dl] & $58 \pm 16$ & $50 \pm 13$ & $53 \pm 15$ \\
\hline T2D duration [years] & $9.4 \pm 7.5$ & $10.6 \pm 8.3$ & $10.1 \pm 8.0$ \\
\hline $\mathrm{HbA}_{1 \mathrm{c}}[\%]$ & $6.8 \pm 1.0$ & $6.9 \pm 1.2$ & $6.8 \pm 1.1$ \\
\hline $\mathrm{HbA}_{1 \mathrm{c}}[\mathrm{mmol} / \mathrm{mol}]$ & $50.8 \pm 12.6$ & $51.9 \pm 10.4$ & $50.8 \pm 11.5$ \\
\hline $\mathrm{HOMA}-\mathrm{IR}^{\dagger}$ & $6.3 \pm 8.5$ & $6.0 \pm 6.7$ & $6.1 \pm 7.4$ \\
\hline Systolic BP [mmHg] & $136 \pm 18$ & $139 \pm 18$ & $138 \pm 18$ \\
\hline Metabolic syndrome $[\%]^{*}$ & 83.5 & 68.8 & 74.6 \\
\hline Coronary artery disease [\%] & 9.7 & 28.4 & 21.1 \\
\hline Acute myocardial infarction [\%] & 6.0 & 15.8 & 11.9 \\
\hline Insulin $[\%]$ & 24.0 & 28.6 & 26.8 \\
\hline Oral antidiabetics [\%] & 76.4 & 76.5 & 76.4 \\
\hline Sulfonylureas [\%] & 13.5 & 21.8 & 18.6 \\
\hline Incretins [\%] & 21.3 & 23.5 & 22.7 \\
\hline
\end{tabular}

Data are expressed as percentage (\%) for categorical variables and mean \pm standard deviation for continuous variables. BMI $=$ body mass index; HDL-C $=$ highdensity lipoprotein cholesterol; $\mathrm{T} 2 \mathrm{D}=$ type 2 diabetes; $\mathrm{BP}=$ blood pressure; $\mathrm{HbA}_{1 \mathrm{c}}=$ glycated hemoglobin; $\mathrm{HOMA}-\mathrm{IR}=$ homeostasis model assessment insulin resistance (fasting, use of long-acting insulin). ${ }^{\dagger} n=413 .{ }^{*}$ Metabolic syndrome is defined according to NCEP criteria [26].

\section{Results}

3.1. Patient Characteristics. Of the 721 patients with T2D that were tested for SDB, 42 patients had incomplete data recordings and could not be analysed (online Supplement Figure S1). Of these, 679 participants were entered into the analysis, of which $39 \%(n=267)$ were women. Patients were $66 \pm 9$ years old, and BMI was $31.0 \pm 5.4 \mathrm{~kg} / \mathrm{m}^{2}$. Their glycated haemoglobin $\left(\mathrm{HbA}_{1 \mathrm{c}}\right)$ was $6.8 \pm 1.1 \%$, and the average duration of T2D was $10.1 \pm 8.0$ years (Table 1 ). Women were of about the same age compared to men, but had a higher BMI $(p<0.001)$ and lower diabetes duration $(p=0.057)$ than men.

Patients with severe SDB were older, predominantly male, and had a significant higher BMI as well as waist-hip ratio compared to patients with no/mild SDB $(p=0.088$, $p=0.002, p<0.001$, and $p<0.001$, resp.) (Table 2). Patients with severe SDB had also a significant larger waist circumference $(p<0.001)$. They showed lower high-density lipoprotein cholesterol (HDL-C) as well as higher systolic blood pressure, higher triglyceride levels, and more severe insulin resistance quantified by homeostasis model assessment (HOMA-IR [23]), but these values were not statistically significant. $\mathrm{HbA}_{1 \mathrm{c}}$ levels and $\mathrm{T} 2 \mathrm{D}$ duration were comparable. Administration of incretin may have implications on prognosis for myocardial infarction in patients with T2D $[24,25]$. In our study, there was no difference in incretin administration between women and men (Table 1) as well as between different severities of SDB (Table 2).
3.2. SDB Parameters. Table 2 presents the different SDB parameters and symptoms. ODI increased with higher severity of SDB. AHI was significantly higher in men than in women (mean 16 versus 11 per hour, resp., $p<0.001$ ), also when patients were divided into different age groups (Figure 1). Additionally, AHI increased between the different age groups $(p=0.102$ in men, $p=0.045$ in women, and $p=0.006$ overall, tested by ANOVA). Furthermore, patients with moderate or severe SDB spent more than 2 hours with $\mathrm{SpO}_{2}<90 \%$ (Table 2).

3.3. The Prevalence of SDB in Patients with T2D. The prevalence of SDB in our study sample was $22 \%$ in women, $41 \%$ in men, and $34 \%$ overall. The prevalence of SDB was significantly higher in men compared to women overall $(p<0.001)$ (Figure 2) and in each age group ( $p=0.004, p=0.001$, and $p=0.009$ ) (Figure 3). Using an alternative definition of clinically relevant $\mathrm{SDB}(\mathrm{AHI} \geq 5 / \mathrm{h}+\mathrm{ESS} \geq 11$ or $\mathrm{AHI} \geq 15 / \mathrm{h})$ led to similar results ( $44 \%$ in men, $24 \%$ in women, and $36 \%$ overall; $p<0.001$ ) (Figure 2). The prevalence of SDB in both men and women increased with age, but this was statistically only significant in the whole sample $(p=0.151$ in men; $p=0.069$ in women; and $p=0.014$ in either sex, tested by logistic regression analysis) (Figure 3 ).

3.4. Modulators Associated with SDB in Patients with Type 2 Diabetes. Using logistic regression by sex, age $\geq 70$ years, BMI $\geq 30 \mathrm{~kg} / \mathrm{m}^{2}$, waist-hip ratio $\geq 0.85$ in women and $\geq 0.9$ in men [27] as well as systolic blood pressure $\geq 130 \mathrm{mmHg}$, and T2D duration were analysed as covariates all in one 
TABLE 2: Clinical and SDB parameters of the 679 analysed participants at the DIACORE baseline visit by SDB class.

\begin{tabular}{|c|c|c|c|c|c|c|}
\hline & $\begin{array}{l}\text { No or mild SDB } \\
\quad(\mathrm{AHI}<15)\end{array}$ & $\begin{array}{l}\text { Moderate SDB } \\
(\mathrm{AHI} \geq 15 \text { to } 29)\end{array}$ & $\begin{array}{l}\text { Severe SDB } \\
(\mathrm{AHI} \geq 30)\end{array}$ & $p$ value $^{\infty}$ & $\begin{array}{c}\text { Moderate versus } \\
\text { no/mild } \mathrm{SDB}^{\S}\end{array}$ & $\begin{array}{l}\text { Severe versus } \\
\text { no/mild } \mathrm{SDB}^{\S}\end{array}$ \\
\hline Number of patients, $n(\%)$ & $451(66 \%)$ & $163(24 \%)$ & $65(10 \%)$ & & & \\
\hline Age [years] & $64 \pm 9$ & $66 \pm 8$ & $67 \pm 7$ & 0.008 & 0.030 & 0.088 \\
\hline Female, $n(\%)$ & $208(46 \%)$ & $43(26 \%)$ & $16(25 \%)$ & $<0.001$ & $<0.001$ & 0.002 \\
\hline BMI $\left[\mathrm{kg} / \mathrm{m}^{2}\right]$ & $30.4 \pm 5.1$ & $31.3 \pm 5.2$ & $34.0 \pm 6.8$ & $<0.001$ & 0.139 & $<0.001$ \\
\hline Waist-hip ratio & $0.95 \pm 0.08$ & $0.98 \pm 0.07$ & $1.00 \pm 0.08$ & $<0.001$ & $<0.001$ & $<0.001$ \\
\hline Waist circumference $[\mathrm{cm}]$ & $99 \pm 16$ & $102 \pm 16$ & $112 \pm 15$ & $<0.001$ & 0.054 & $<0.001$ \\
\hline Triglycerides $[\mathrm{mg} / \mathrm{dl}]$ & $166 \pm 125$ & $181 \pm 155$ & $187 \pm 107$ & 0.273 & 0.597 & 0.699 \\
\hline $\mathrm{HDL}-\mathrm{C}[\mathrm{mg} / \mathrm{dl}]$ & $54 \pm 16$ & $51 \pm 14$ & $50 \pm 13$ & 0.016 & 0.080 & 0.080 \\
\hline T2D duration [years] & $10 \pm 7$ & $12 \pm 10$ & $9 \pm 7$ & 0.001 & 0.001 & 1.000 \\
\hline $\mathrm{HbA}_{1 \mathrm{c}}[\%]$ & $6.8 \pm 1.1$ & $6.9 \pm 1.2$ & $6.6 \pm 0.7$ & 0.111 & 0.867 & 0.340 \\
\hline $\mathrm{HbA}_{1 \mathrm{c}}[\mathrm{mmol} / \mathrm{mol}]$ & $51 \pm 7$ & $52 \pm 8$ & $49 \pm 5$ & 0.111 & 0.867 & 0.340 \\
\hline $\mathrm{HOMA}^{-\mathrm{IR}^{\dagger}}$ & $5.6 \pm 5.9$ & $6.7 \pm 9.1$ & $7.9 \pm 10.9$ & 0.137 & 0.607 & 0.242 \\
\hline Systolic BP [mmHg] & $137 \pm 18$ & $140 \pm 19$ & $141 \pm 17$ & 0.041 & 0.135 & 0.179 \\
\hline Metabolic syndrome [\%] * & 71.8 & 78.4 & 84.6 & 0.038 & 0.290 & 0.079 \\
\hline Coronary artery disease [\%] & 16.0 & 23.3 & 20.0 & 0.101 & 0.083 & 0.235 \\
\hline $\begin{array}{l}\text { Acute myocardial } \\
\text { infarction }[\%]\end{array}$ & 10.9 & 13.5 & 15.4 & 0.448 & 1.000 & 0.882 \\
\hline Insulin [\%] & 22.6 & 37.4 & 29.2 & 0.001 & 0.001 & 0.771 \\
\hline Oral antidiabetics [\%] & 77.6 & 74.2 & 73.8 & 0.601 & 1.000 & 1.000 \\
\hline Sulfonylureas [\%] & 19.3 & 18.4 & 13.8 & 0.573 & 1.000 & 0.877 \\
\hline Incretins [\%] & 24.4 & 18.4 & 21.5 & 0.288 & 0.355 & 1.000 \\
\hline \multicolumn{7}{|l|}{ SDB parameters } \\
\hline AHI $[/ h]$ & $7 \pm 4$ & $21 \pm 4$ & $46 \pm 12$ & 0.001 & $<0.001$ & $<0.001$ \\
\hline ODI $[/ \mathrm{h}]$ & $7 \pm 5$ & $20 \pm 5$ & $41 \pm 12$ & 0.001 & $<0.001$ & $<0.001$ \\
\hline $\mathrm{SpO}_{2}<90 \%[\mathrm{~min}]$ & $73 \pm 106$ & $125 \pm 122$ & $120 \pm 85$ & 0.001 & $<0.001$ & 0.004 \\
\hline $\mathrm{SpO}_{2}[\%]$ & $93 \pm 2$ & $92 \pm 2$ & $92 \pm 2$ & 0.001 & $<0.001$ & $<0.001$ \\
\hline $\operatorname{Min} \mathrm{SpO}_{2}[\%]$ & $80 \pm 12$ & $75 \pm 16$ & $74 \pm 15$ & 0.001 & 0.001 & 0.002 \\
\hline $\begin{array}{l}\text { Nocturnal breathing } \\
\text { rate }[/ \mathrm{min}]\end{array}$ & $15 \pm 3$ & $14 \pm 3$ & $12 \pm 3$ & 0.001 & 0.064 & $<0.001$ \\
\hline Nocturnal heart rate $[/ \mathrm{min}]$ & $66 \pm 9$ & $66 \pm 10$ & $67 \pm 10$ & 0.667 & 1.000 & 1.000 \\
\hline ESS & $5.1 \pm 3.3$ & $5.4 \pm 3.6$ & $5.9 \pm 3.1$ & 0.148 & 1.000 & 0.195 \\
\hline $\mathrm{ESS} \geq 11, n(\%)$ & $29(6.5)$ & $10(6.4)$ & $6(9.5)$ & 0.661 & 1.000 & 1.000 \\
\hline Nocturia ( $\geq 3 \mathrm{x} /$ night) [\%] & $64(14 \%)$ & $25(16 \%)$ & $11(17 \%)$ & 0.785 & 1.000 & 1.000 \\
\hline
\end{tabular}

Data are expressed as percentage (\%) for categorical variables and mean \pm standard deviation for continuous variables. ${ }^{\infty}$ Difference of parameters between the three SDB groups assessed by chi-square tests for categorical variables and by ANOVA for continuous variables. ${ }^{\mathfrak{S}}$ Difference of parameters between two SDB groups assessed by post hoc analysis (Bonferroni). $p<0.05$ was considered statistically significant and marked in bold. SDB = sleep-disordered breathing; $\mathrm{BMI}=$ body mass index; HDL-C = high-density lipoprotein cholesterol; $\mathrm{T} 2 \mathrm{D}=$ type 2 diabetes; $\mathrm{BP}=$ blood pressure; $\mathrm{HbA}_{1 \mathrm{c}}=$ glycated hemoglobin; $\mathrm{HOMA}-$ $\mathrm{IR}=$ homeostasis model assessment insulin resistance (fasting, use of long-acting insulin); AHI = apnoea-hypopnoea index; ODI = oxygen desaturation index; $\mathrm{SpO}_{2}=$ peripheral oxygen saturation; ESS = Epworth Sleepiness Scale. ${ }^{\dagger} n=413 .{ }^{*}$ Metabolic syndrome is defined according to NCEP criteria [26].

model to investigate an association with $\mathrm{SDB}(\mathrm{AHI} \geq 15 / \mathrm{h})$. In women, age $\geq 70$ years (OR $1.95,95 \%$ CI $[1.04,3.66]$, $p=0.039$ ) and systolic blood pressure $\geq 130 \mathrm{mmHg}$ (OR $2.09,95 \%$ CI $[1.09,4.02], p=0.026)$ were significantly and independently associated with $\mathrm{SDB} . \mathrm{BMI} \geq 30 \mathrm{~kg} / \mathrm{m}^{2}$, waist-hip ratio $\geq 0.85$, and $\mathrm{T} 2 \mathrm{D}$ duration were not significantly associated with SDB (OR 1.56 [0.82, 2.97], $p=0.175 ;$ OR $2.64[0.97,7.14], p=0.057$; and OR 0.99 $[0.95,1.04], p=0.733$, resp.).

In men, BMI $\geq 30 \mathrm{~kg} / \mathrm{m}^{2}$ (OR 2.27, 95\% CI [1.49, 3.47], $p<0.001$ ) and T2D duration (per year; OR $1.03,95 \% \mathrm{CI}$
$[1.00,1.05], p=0.033)$ were significant and independent modulators were associated with SDB. Age $\geq 70$ years, waist-hip ratio $\geq 0.9$, and systolic blood pressure $\geq 130 \mathrm{mmHg}$ were not significantly associated with SDB in men (OR 1.52 $[0.97,2.37], p=0.056$; OR $1.05[0.37,2.96], p=0.929$; and OR $1.10[0.70,1.73], p=0.676$, resp.).

Using a general regression model including both sexes with sex, age $\geq 70$ years, $B M I \geq 30 \mathrm{~kg} / \mathrm{m}^{2}$, waist-hip ratio $\geq 0.85$, systolic blood pressure $\geq 130 \mathrm{mmHg}$, and T2D duration as covariates, besides age $\geq 70$ years (OR 1.65, 95\% CI $1.2,2.4, p=0.007)$ and $\mathrm{BMI} \geq 30 \mathrm{~kg} / \mathrm{m}^{2}(\mathrm{OR} 2.08,95 \% \mathrm{CI}$ 


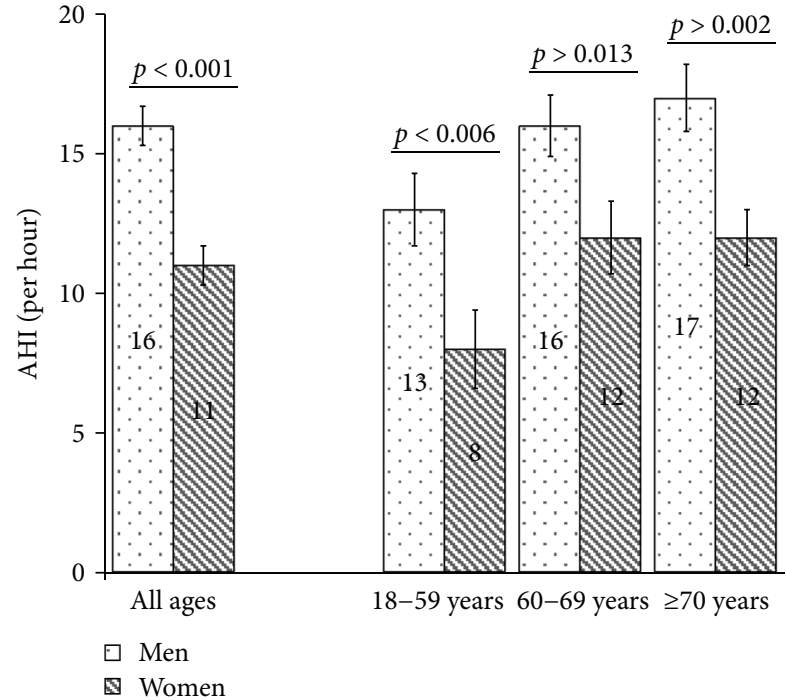

Figure 1: Apnoea-hypopnoea index (AHI) in men and women of the total sample $(n=679)$ and of different age groups (18-59, $60-69$, and $\geq 70$ years $)(n=164, n=286$, and $n=229)$, stating mean values in the bar and including standard errors and $p$ values from $t$-tests. AHI was significantly higher in men than in women in the whole sample as well as in different age groups.

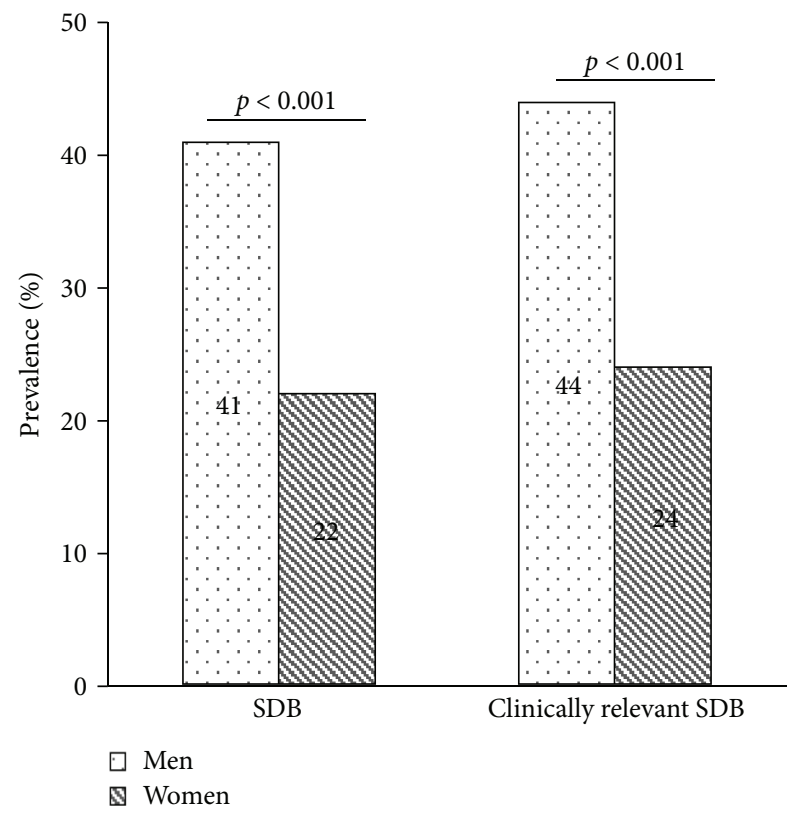

FIgURE 2: Bar charts showing the prevalence of sleep-disordered breathing (SDB) and clinically relevant SDB (AHI $\geq 5 / \mathrm{h}+\mathrm{ESS} \geq 11$ or $A H I \geq 15 / h$ ) in 412 men and 267 women (\%); $p$ values assessed by chi-square tests. $n=679$. SDB as well as clinically relevant SDB was significantly more present in men than in women.

$1.5,3.0, p<0.001)$, only male sex was independently associated with SDB (OR 2.57, 95\% CI 1.7, 3.8, $p<0.001$ ). $\mathrm{WHR} \geq 0.85$, systolic blood pressure $\geq 130 \mathrm{mmHg}$, and T2D duration were not significantly associated with SDB in either sex (OR 1.87, 95\% CI [0.8, 4.4], $p=0.156$; OR 1.37, 95\% CI

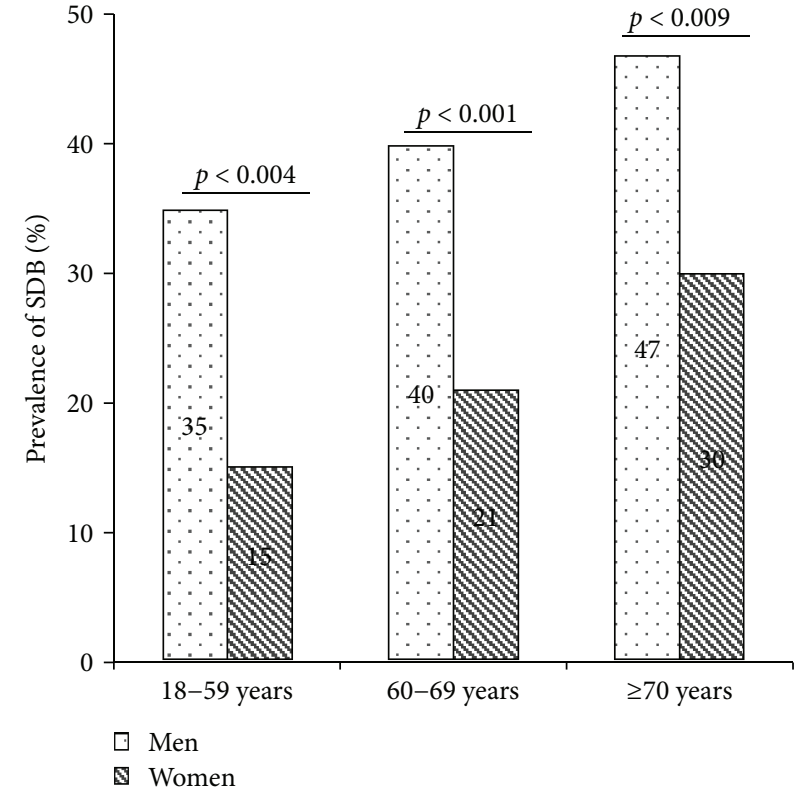

FIgURE 3: Bar charts with the prevalence of sleep-disordered breathing (SDB) in men and women in different age groups (\%); $p$ values were assessed by chi-square tests. $n=679$. SDB was significantly more present in men than in women in each age group.

$[1.0,2.0], p=0.091 ;$ and OR 1.02, 95\% CI $[0.99,1.04]$, $p=0.106$, resp.).

In regression models with all covariates listed above plus including interaction terms of each of the other covariates with sex, no interaction with sex was detected (interaction terms for age $\geq 70$ years, $B M I \geq 30 \mathrm{~kg} / \mathrm{m}^{2}, \quad W H R \geq 0.85$, systolic blood pressure $\geq 130 \mathrm{mmHg}$, and T2D duration: $p=0.527, p=0.333, p=0.999, p=0.128$, and $p=0.280$, resp.). Thus, modulators for SDB seem to be similar in men and women.

3.5. Modulators Associated with AHI in Patients with Type 2 Diabetes. Linear regression analysis (Table 3 ) showed that a higher AHI was independently associated with higher age, higher BMI, and higher waist-hip ratio in women. In men, only age and BMI, but not waist-hip ratio, were significantly associated with AHI.

In the entire sample, male sex, age, BMI, and waist-hip ratio were associated with a higher AHI independent of the other covariates. Systolic blood pressure and T2D duration showed no significant association with AHI in either sex.

Adding an interaction term of waist-hip ratio with sex to the regression model stated above, no interaction with sex was detected (interaction $p=0.503$ ). Thus, modulators for a higher AHI seem to be similar in men and women.

Both, metabolic syndrome and SDB are known to promote cardiovascular disease and arrhythmia [28-30]. Due to this, we added metabolic syndrome to the multivariable analysis and it appeared as a significant modulator of AHI in the whole sample $(B=5.139 ; 95 \%$ CI 2.913, 7.364; $p<0.001)$ as well as in women $(B=5.099 ; 95 \%$ CI 1.422 , 
TABLE 3: Linear regression analysis: factors associated with AHI in the total population, in 267 women and in 412 men.

\begin{tabular}{|c|c|c|c|c|}
\hline \multirow{2}{*}{ Variable } & \multicolumn{2}{|c|}{ Univariable analysis } & \multicolumn{2}{|c|}{ Multivariable analysis } \\
\hline & $B(95 \% \mathrm{CI})$ & $p$ value & $B(95 \% \mathrm{CI})$ & $p$ value \\
\hline \multicolumn{5}{|l|}{ Total population $(n=679)$} \\
\hline Female sex & $-4.75(-6.74,-2.76)$ & $<0.001$ & $-3.54(-6.06,-1.02)$ & 0.006 \\
\hline Age [per 10 years] & $1.70(0.59,2.81)$ & 0.003 & $2.55(1.40,3.70)$ & $<0.001$ \\
\hline BMI [per 5 units] & $2.99(2.10,3.88)$ & $<0.001$ & $3.48(2.53,4.44)$ & $<0.001$ \\
\hline Waist-hip ratio [per 0.1 unit] & $4.48(3.25,5.71)$ & $<0.001$ & $2.35(0.77,3.94)$ & 0.004 \\
\hline Systolic BP & $0.08(0.03,0.13)$ & 0.004 & $0.02(-0.04,0.07)$ & 0.508 \\
\hline $\mathrm{T} 2 \mathrm{D}$ duration & $0.09(-0.04,0.21)$ & 0.165 & $-0.004(-0.13,0.12)$ & 0.952 \\
\hline \multicolumn{5}{|l|}{ Women $(n=267)$} \\
\hline Age [per 10 years] & $1.92(0.49,3.35)$ & 0.009 & $2.35(0.83,3.87)$ & 0.003 \\
\hline BMI [per 5 units] & $2.00(0.87,3.13)$ & 0.001 & $2.05(0.88,3.21)$ & 0.001 \\
\hline Waist-hip ratio [per 0.1 units] & $3.24(1.13,5.35)$ & 0.003 & $2.29(0.18,4.40)$ & 0.034 \\
\hline Systolic BP & $0.08(0.01,0.16)$ & 0.037 & $0.03(-0.05,0.11)$ & 0.446 \\
\hline T2D duration & $0.06(-0.13,0.25)$ & 0.527 & $-0.02(-0.02,0.17)$ & 0.826 \\
\hline \multicolumn{5}{|l|}{$\operatorname{Men}(n=412)$} \\
\hline Age [per 10 years] & $1.41(-0.19,3.01)$ & 0.084 & $2.76(1.09,4.43)$ & 0.001 \\
\hline BMI [per 5 units] & $4.75(3.45,6.06)$ & $<0.001$ & $5.25(3.73,6.77)$ & $<0.001$ \\
\hline Waist-hip ratio [per 0.1 units] & $4.92(2.71,7.12)$ & $<0.001$ & $1.59(-0.77,3.94)$ & 0.185 \\
\hline Systolic BP & $0.06(-0.01,0.14)$ & 0.091 & $0.01(-0.06,0.09)$ & 0.739 \\
\hline T2D duration & $0.07(-0.09,0.23)$ & 0.393 & $0.01(-0.15,0.17)$ & 0.882 \\
\hline
\end{tabular}

$\mathrm{AHI}=$ apnoea-hypopnoea index; $B=$ unstandardized regression coefficient; $95 \% \mathrm{CI}=95 \%$ confidence interval; $\mathrm{BMI}=\mathrm{body} \quad \mathrm{mass}$ index; $\mathrm{T} 2 \mathrm{D}$ duration $=$ duration of type 2 diabetes; $\mathrm{BP}=$ blood pressure.

$8.776 ; p=0.007)$ and in men $(B=5.186 ; 95 \%$ CI 2.350 , 8.022; $p<0.001)$.

\section{Discussion}

The present study investigating SDB in 679 patients with T2D obtained several key findings. First, moderate to severe $\mathrm{SDB}$, defined as $\mathrm{AHI} \geq 15 / \mathrm{h}$, is present in more than a third of our patients with T2D. Second, the prevalence of moderate to severe SDB increases with age and is more common in men than in women yielding a prevalence of $40 \%$ and $21 \%$ in our sample of 60 to 69-year-old men or women, respectively. Third, age, BMI, and waist-hip ratio are significant and independent modulators were associated with higher AHI. There were no significant differences of these effects between men and women.

The prevalence of SDB in community samples was modestly lower than in samples of patients with T2D. In obese participants of the same age group with a BMI (30.0 to $39.9 \mathrm{~kg} / \mathrm{m}^{2}$ ) as seen in our sample, $29 \%$ of men and $14 \%$ of women have SDB [5].

Our results of $34 \%$ of patients with T2D with SDB are consistent with the seven prior studies including more than 150 patients with T2D and using polysomnography or SDB monitoring devices for diagnosis of SDB (Table 4). Differences in prevalence could be explained by differences in participant recruiting, patient characteristics, definitions of sleep apnoea, or methods of monitoring for SDB (Table 4 and online Supplement Table S2).
Some studies showed higher prevalence estimates than our study $[12,31]$ (Table 4). The reason for these higher prevalence estimates might be explained by a higher BMI of participants (Foster et al. BMI $=36.5 \pm 5.8 \mathrm{~kg} / \mathrm{m}^{2}$, Schober et al. $\mathrm{BMI}=32.6 \pm 6.7 \mathrm{~kg} / \mathrm{m}^{2}$, and $\mathrm{BMI}=31.0 \pm 5.4 \mathrm{~kg} / \mathrm{m}^{2}$ in the DIACORE SDB substudy) [12,31] since obesity is a known risk factor for $\operatorname{SDB}[1,32,33]$.

Other studies showed lower prevalence estimates. The patient populations of those studies had significantly lower BMI $\left(25.1 \pm 3.6 \mathrm{~kg} / \mathrm{m}^{2}\right)$ [34] or were significantly younger $[10,13]$.

Similar to previous studies [31, 35], we found a higher prevalence of SDB in men than in women.

In previous studies, varied information about the modulators of SDB in patients with diabetes has been presented. Lam et al. found that male sex, higher age as well as BMI, and diastolic blood pressure were independently associated with AHI [35]. In the present study, age, BMI, and waist-hip ratio were significantly associated with AHI.

Even if there were no significant differences in modulators for a higher $\mathrm{AHI}$ between the sexes, waist-hip ratio showed an association with AHI in women in the DIACORE substudy. This finding might be explained by the differences in the distribution of bodily fat between the sexes. In women, fat accumulation in the hip region is more common compared to men [36]. Therefore, it is possible that the effect of a pathologically increased waist-hip ratio on AHI could be higher in women than in men. 


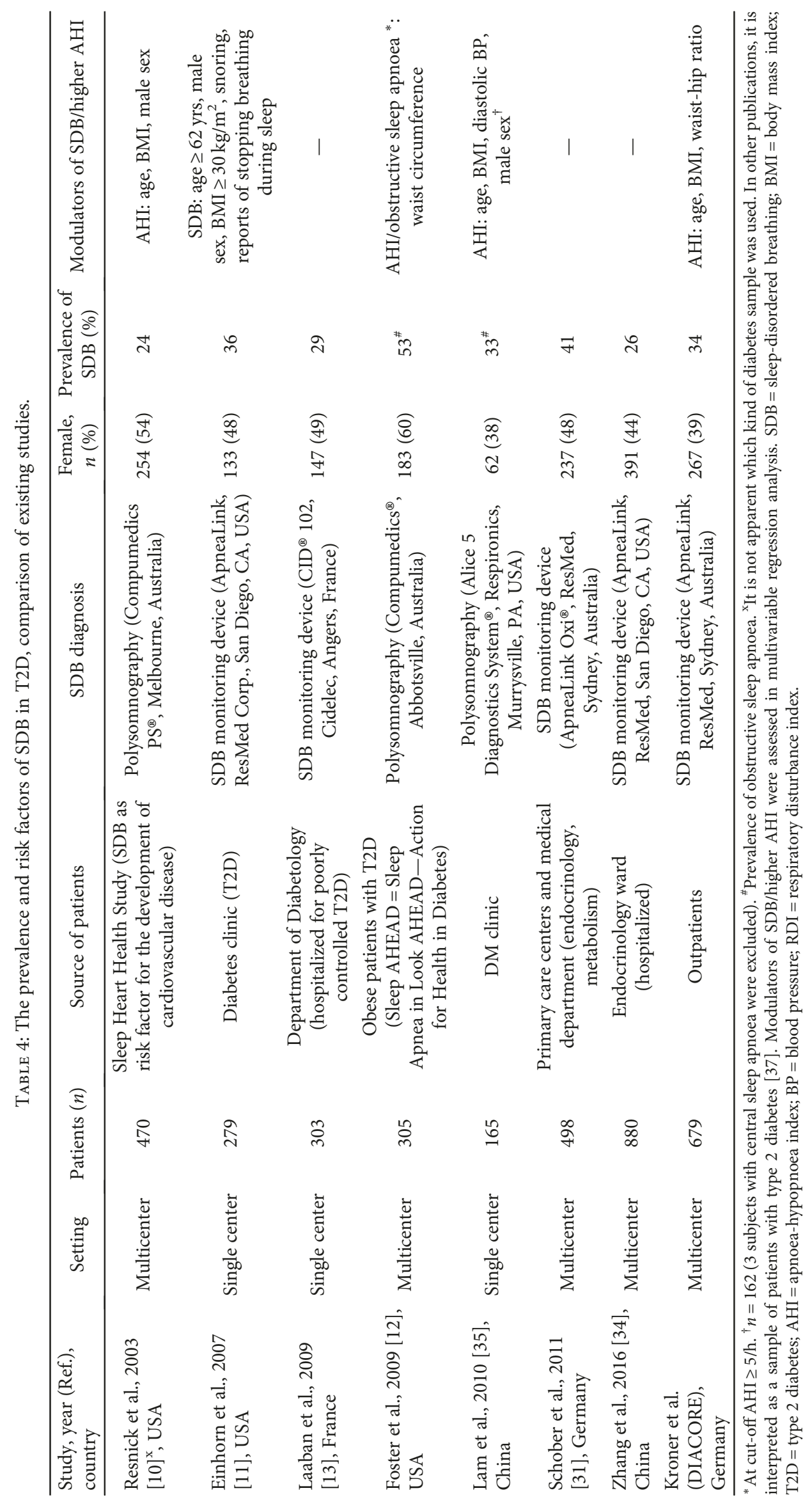


There is evidence that diabetes and its level of severity could contribute to the development of SDB and its worsening $[38,39]$. Although this was only a cross-sectional analysis, our data do not support this hypothesis, since $\mathrm{HbA}_{1 \mathrm{c}}$, HOMA-IR, and the duration of diabetes were not associated with the presence or severity of SDB.

On the other hand, there is evidence that SDB may contribute to impaired glucose metabolism [40]. Studies investigating the effects of treatment of obstructive sleep apnoea with continuous positive airway pressure show different results. In a randomized controlled trial, this therapy significantly improved glucose tolerance [41]. However, other studies did not find any changes in glycaemic control $[42,43]$.

Particularly, T2D results in very high economic and social costs [1]. Due to the evidence of a mutual impact of T2D and SDB, the high proportion of SDB in patients with T2D, and the clinical relevance, monitoring for SDB might be profitable as this proportion of patients could benefit from SDB therapy.

Especially patients with typical symptoms like daytime sleepiness, heavy snoring or already occurring apnoeas should be tested for SDB [33, 44], because treatment of SDB with continuous positive airway pressure improves quality of life and daytime sleepiness, even in patients with mild SDB-related symptoms [9, 45]. Additionally, physicians treating patients with SDB should also consider the possibility of T2D and should initiate appropriate tests or measures [33].

The strengths of our study are the large sample size and high-resolution phenotyping of a T2D outpatient cohort with a comparable number of men and women $(61 \% / n=412$ versus $39 \% / n=267)$, thus enabling us to investigate effects specific to sex and using multivariable modelling. It expands on the knowledge from previous studies that were restricted to a clinically more severe diabetes status.

There are also some limitations that warrant discussion: first, although the use of portable respiratory devices instead of inpatient overnight polysomnography is well established and validated for assessment of $\operatorname{SDB}[18,19]$, we cannot distinguish between obstructive and central sleep apnoea due to simplified monitoring. Second, left ventricular ejection fraction and heart failure were not evaluated in DIACORE, so we cannot report on their implications on the present study. Third, our sample might not be fully representative of an overall T2D patient group, because we did not standardize prevalence estimates to a specific population.

\section{Conclusions}

More than one-third of patients with T2D had moderate to severe sleep-disordered breathing, which was more common in men than in women. Higher age, higher BMI, and higher waist-hip ratio were associated with higher AHI. Modulators for higher AHI were similar in men and in women. Testing for SDB in patients with type 2 diabetes is recommended and vice versa.

\section{Conflicts of Interest}

M. Arzt received research grants from ResMed, Philips Respironics, and the ResMed Foundation and also received lecture fees from Philips Respironics and ResMed. C. A. Böger has received funding from the KfH Stiftung Präventivmedizin e.V., the Else Kröner-Fresenius-Stiftung, and the Dr. Robert Pfleger Stiftung. All other authors declare that there is no conflict of interest regarding the publication of this article.

\section{Authors' Contributions}

T. Kroner, S. Stadler, and M. Arzt were involved in the conception, hypotheses delineation, design of the study, analysis and interpretation of obtained information, writing of the article, and its revision prior to submission. C. A. Böger is the DIACORE study PI and was involved in the design of this substudy, acquisition and interpretation of the data, and critical revision of the article prior to submission. T. Kroner and M. Rheinberger were involved in the acquisition and interpretation of the data and critical revision of the article prior to submission. M. Gorski and I. M. Heid helped in statistical analysis and drafting of the manuscript. All authors read and approved the final manuscript. S. Stadler is the guarantor of this work and, as such, had full access to all the data in the study and takes responsibility for the integrity of the data and the accuracy of the data analysis. T. Kroner and M. Arzt contributed equally to this work.

\section{Acknowledgments}

The authors thank all participating patients of the DIACORE study. The authors thank the physicians and health insurance companies for supporting the DIACORE study: Axel Andreae, Gerhard Haas, Sabine Haas, Jochen Manz, Johann Nusser, Günther Kreisel, Gerhard Bawidamann, Frederik Mader, Susanne Kißkalt, Johann Hartl, Thomas Segiet, Christiane Gleixner, Christian Scholz, Monika Schober (Chief of Supply Management, Allgemeine Ortskrankenkasse Bayern), Cornelia Heinrich (Communication Manager, Allgemeine Ortskrankenkasse Bayern), Thomas Bohnhoff (Disease Management, Techniker Krankenkasse), Thomas Heilmann (Head of Disease Management, Techniker Krankenkasse), Stefan Stern (Consulting Physician, Allgemeine Ortskrankenkasse Bayern), Andreas Utz (Department Head, Allgemeine Ortskrankenkasse Bayern), Georg Zellner (Chief of Supply Management, Deutsche Angestellten Krankenkasse), Werner Ettl (Barmer-GEK), Thomas Buck (Barmer-GEK), Rainer Bleek (IKK classic), and Ulrich Blaudzun (IKK classic). The authors further thank the study nurses for their expert work in performing the study visits: Simone Neumeier, Sarah Hufnagel, Isabel Haller, Petra Jackermeier, Sabrina Obermüller, Christiane Ried, Ulrike Hanauer, Bärbel Sendtner, and Natalia Riewe-Kerow. Konstantin Dumann and Britta Hörmann (PhD students) are also thanked for their expert work in performing the study visits. 


\section{Supplementary Materials}

Supplement Figure S1: study flowchart showing the recruitment of the participants. SDB = sleep-disordered breathing. Supplement Table S2: different diagnostic devices and scoring criteria for respiratory events in similar studies. (Supplementary Materials)

\section{References}

[1] International Diabetes Federation, IDF DiabetesInternational Diabetes Federation, Brussels, Belgium, 7 editionJune 2016, http://www.diabetesatlas.org/.

[2] L. Chen, D. J. Magliano, and P. Z. Zimmet, "The worldwide epidemiology of type 2 diabetes mellitus-present and future perspectives," Nature Reviews Endocrinology, vol. 8, no. 4, pp. 228-236, 2011.

[3] H. F. Becker, A. Jerrentrup, T. Ploch et al., "Effect of nasal continuous positive airway pressure treatment on blood pressure in patients with obstructive sleep apnea," Circulation, vol. 107, no. 1, pp. 68-73, 2003.

[4] G. Mayer, M. Arzt, B. Braumann et al., "S3-Leitlinie Nicht erholsamer Schlaf/Schlafstörungen - Kapitel, Schlafbezogene Atmungsstörungen," Somnologie, vol. 20, Supplement 2, pp. 97-180, 2017.

[5] P. E. Peppard, T. Young, J. H. Barnet, M. Palta, E. W. Hagen, and K. M. Hla, "Increased prevalence of sleep-disordered breathing in adults," American Journal of Epidemiology, vol. 177, no. 9, pp. 1006-1014, 2013.

[6] T. Young, P. E. Peppard, and D. J. Gottlieb, "Epidemiology of obstructive sleep apnea: a population health perspective," American Journal of Respiratory and Critical Care Medicine, vol. 165, no. 9, pp. 1217-1239, 2002.

[7] N. McArdle and N. J. Douglas, "Effect of continuous positive airway pressure on sleep architecture in the sleep apneahypopnea syndrome: a randomized controlled trial," American Journal of Respiratory and Critical Care Medicine, vol. 164, no. 8, pp. 1459-1463, 2001.

[8] A. Hetzenecker, T. Roth, C. Birner, L. S. Maier, M. Pfeifer, and M. Arzt, "Adaptive servo-ventilation therapy of central sleep apnoea and its effect on sleep quality," Clinical Research in Cardiology, vol. 105, no. 3, pp. 189-195, 2016.

[9] S. E. Craig, M. Kohler, D. Nicoll et al., "Continuous positive airway pressure improves sleepiness but not calculated vascular risk in patients with minimally symptomatic obstructive sleep apnoea: the MOSAIC randomised controlled trial," Thorax, vol. 67, no. 12, pp. 1090-1096, 2012.

[10] H. E. Resnick, S. Redline, E. Shahar et al., "Diabetes and sleep disturbances: findings from the Sleep Heart Health Study," Diabetes Care, vol. 26, no. 3, pp. 702-709, 2003.

[11] D. Einhorn, D. A. Stewart, M. Erman, N. Gordon, A. PhilisTsimikas, and E. Casal, "Prevalence of sleep apnea in a population of adults with type 2 diabetes mellitus," Endocrine Practice, vol. 13, no. 4, pp. 355-362, 2007.

[12] G. D. Foster, M. H. Sanders, R. Millman et al., "Obstructive sleep apnea among obese patients with type 2 diabetes," Diabetes Care, vol. 32, no. 6, pp. 1017-1019, 2009.

[13] J. P. Laaban, S. Daenen, D. Léger et al., "Prevalence and predictive factors of sleep apnoea syndrome in type 2 diabetic patients," Diabetes \& Metabolism, vol. 35, no. 5, pp. 372-377, 2009.
[14] T. Young, R. Hutton, L. Finn, S. Badr, and M. Palta, "The gender bias in sleep apnea diagnosis. Are women missed because they have different symptoms?," Archives of Internal Medicine, vol. 156, no. 21, pp. 2445-2451, 1996.

[15] O. K. Basoglu and M. S. Tasbakan, "Gender differences in clinical and polysomnographic features of obstructive sleep apnea: a clinical study of 2827 patients," Sleep \& Breathing, vol. 22, no. 1, pp. 241-249, 2018.

[16] S. Stadler, T. Zimmermann, F. Franke et al., "Association of sleep-disordered breathing with diabetes-associated kidney disease," Annals of Medicine, vol. 49, no. 6, pp. 487-495, 2017.

[17] L. Dörhöfer, for the DIACORE Study Group, A. Lammert et al., "Study design of DIACORE (DIAbetes COhoRtE) - a cohort study of patients with diabetes mellitus type 2," BMC Medical Genetics, vol. 14, no. 1, p. 25, 2013.

[18] M. K. Erman, D. Stewart, D. Einhorn, N. Gordon, and E. Casal, "Validation of the ApneaLink for the screening of sleep apnea: a novel and simple single-channel recording device," Journal of Clinical Sleep Medicine, vol. 3, no. 4, pp. 387-392, 2007.

[19] M. Arzt, H. Woehrle, O. Oldenburg et al., "Prevalence and predictors of sleep-disordered breathing in patients with stable chronic heart failure: the SchlaHF registry," JACC: Heart Failure, vol. 4, no. 2, pp. 116-125, 2016.

[20] B. A. Stuck and H. G. Weeß, "The new "international classification of sleep disorders". A critical acclaim of diagnostic criteria for sleep disordered breathing," Somnologie - Schlafforschung und Schlafmedizin, vol. 19, no. 2, pp. 126132, 2015.

[21] G. Weinreich, J. Armitstead, V. Topfer, Y.-M. Wang, Y. Wang, and H. Teschler, "Validation of ApneaLink as screening device for Cheyne-Stokes respiration,” Sleep, vol. 32, no. 4, pp. 553557, 2009.

[22] M. W. Johns, "A new method for measuring daytime sleepiness: the Epworth sleepiness scale," Sleep, vol. 14, no. 6, pp. 540-545, 1991.

[23] D. R. Matthews, J. P. Hosker, A. S. Rudenski, B. A. Naylor, D. F. Treacher, and R. C. Turner, "Homeostasis model assessment: insulin resistance and beta-cell function from fasting plasma glucose and insulin concentrations in man," Diabetologia, vol. 28, no. 7, pp. 412-419, 1985.

[24] R. Marfella, C. Sardu, P. Calabrò et al., "Non-ST-elevation myocardial infarction outcomes in patients with type 2 diabetes with non-obstructive coronary artery stenosis: effects of incretin treatment," Diabetes, Obesity and Metabolism, vol. 20, no. 3, pp. 723-729, 2018.

[25] R. Marfella, C. Sardu, M. L. Balestrieri et al., "Effects of incretin treatment on cardiovascular outcomes in diabetic STEMIpatients with culprit obstructive and multivessel non obstructive-coronary-stenosis," Diabetology \& Metabolic Syndrome, vol. 10, no. 1, p. 1, 2018.

[26] Third Report of the National Cholesterol Education Program (NCEP) Expert Panel on Detection, "Evaluation, and treatment of high blood cholesterol in adults (adult treatment panel III) final report," Circulation, vol. 106, no. 25, pp. 31433421, 2002.

[27] World Health Organization, Waist Circumference and WaistHip Ratio: Report of a WHO Expert Consultation, Geneva, 2008June 23, 2016, http://apps.who.int/iris/bitstream/10665/ 44583/1/9789241501491_eng.pdf?ua=1.

[28] C. Sardu, M. Santamaria, S. Funaro et al., "Cardiac electrophysiological alterations and clinical response in cardiac 
resynchronization therapy with a defibrillator treated patients affected by metabolic syndrome," Medicine, vol. 96, no. 14, article e6558, 2017.

[29] C. Sardu, G. Carreras, S. Katsanos et al., "Metabolic syndrome is associated with a poor outcome in patients affected by outflow tract premature ventricular contractions treated by catheter ablation," BMC Cardiovascular Disorders, vol. 14, no. 1, p. 176, 2014.

[30] R. H. Eckel, S. M. Grundy, and P. Z. Zimmet, "The metabolic syndrome," Lancet, vol. 365, no. 9468, pp. 1415-1428, 2005.

[31] A. K. Schober, M. F. Neurath, and I. A. Harsch, "Prevalence of sleep apnoea in diabetic patients," The Clinical Respiratory Journal, vol. 5, no. 3, pp. 165-172, 2011.

[32] T. Young, M. Palta, J. Dempsey, J. Skatrud, S. Weber, and S. Badr, "The occurrence of sleep-disordered breathing among middle-aged adults," The New England Journal of Medicine, vol. 328, no. 17, pp. 1230-1235, 1993.

[33] International Diabetes Federation, The IDF Consensus Statement on Sleep Apnoea and Type 2 DiabetesInternational Diabetes Federation, Brussels, BelgiumJune 2016, http://www. idf.org/webdata/docs/APNOEA_final.pdf.

[34] P. Zhang, R. Zhang, F. Zhao et al., "The prevalence and characteristics of obstructive sleep apnea in hospitalized patients with type 2 diabetes in China," Journal of Sleep Research, vol. 25, no. 1, pp. 39-46, 2016.

[35] D. C. Lam, M. M. Lui, J. C. Lam, L. H. Y. Ong, K. S. L. Lam, and M. S. M. Ip, "Prevalence and recognition of obstructive sleep apnea in Chinese patients with type 2 diabetes mellitus," Chest, vol. 138, no. 5, pp. 1101-1107, 2010.

[36] H. Guo, L. Zhang, C. Zhu et al., "A single nucleotide polymorphism in the FADS1 gene is associated with plasma fatty acid and lipid profiles and might explain gender difference in body fat distribution," Lipids in Health and Disease, vol. 16, no. 1, p. 67, 2017.

[37] S. Pamidi and E. Tasali, "Obstructive sleep apnea and type 2 diabetes: is there a link?," Frontiers in Neurology, vol. 3, p. 126, 2012

[38] J. H. Ficker, S. H. Dertinger, W. Siegfried et al., "Obstructive sleep apnoea and diabetes mellitus: the role of cardiovascular autonomic neuropathy," The European Respiratory Journal, vol. 11, no. 1, pp. 14-19, 1998.

[39] P. Bottini, M. L. Dottorini, M. Cristina Cordoni, G. Casucci, and C. Tantucci, "Sleep-disordered breathing in nonobese diabetic subjects with autonomic neuropathy," The European Respiratory Journal, vol. 22, no. 4, pp. 654-660, 2003.

[40] K. A. Stamatakis and N. M. Punjabi, "Effects of sleep fragmentation on glucose metabolism in normal subjects," Chest, vol. 137, no. 1, pp. 95-101, 2010.

[41] E. Martínez-Cerón, B. Barquiel, A. M. Bezos et al., "Effect of continuous positive airway pressure on glycemic control in patients with obstructive sleep apnea and type 2 diabetes. A randomized clinical trial," American Journal of Respiratory and Critical Care Medicine, vol. 194, no. 4, pp. 476-485, 2016.

[42] J. E. Shaw, N. M. Punjabi, M. T. Naughton et al., "The effect of treatment of obstructive sleep apnea on glycemic control in type 2 diabetes," American Journal of Respiratory and Critical Care Medicine, vol. 194, no. 4, pp. 486-492, 2016.

[43] S. D. West, D. J. Nicoll, T. M. Wallace, D. R. Matthews, and J. R. Stradling, "Effect of CPAP on insulin resistance and HbA1c in men with obstructive sleep apnoea and type 2 diabetes," Thorax, vol. 62, no. 11, pp. 969-974, 2007.
[44] G. Mayer, M. Arzt, B. Braumann et al., "German S3 guideline nonrestorative sleep/sleep disorders, chapter "sleep-related breathing disorders in adults," short version," Somnologie, vol. 21, no. 4, pp. 290-301, 2017.

[45] R. D. McEvoy, N. A. Antic, E. Heeley et al., "CPAP for prevention of cardiovascular events in obstructive sleep apnea," The New England Journal of Medicine, vol. 375, no. 10, pp. 919931, 2016. 


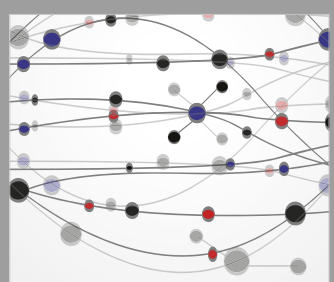

The Scientific World Journal
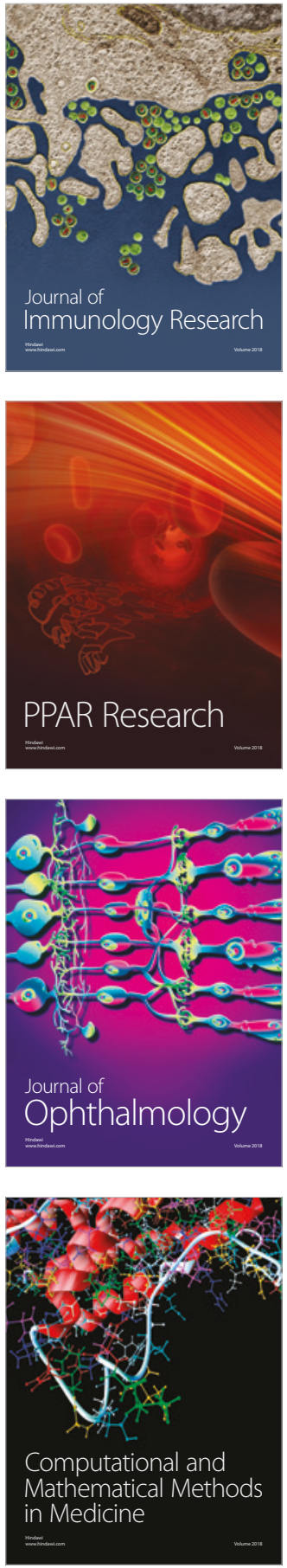

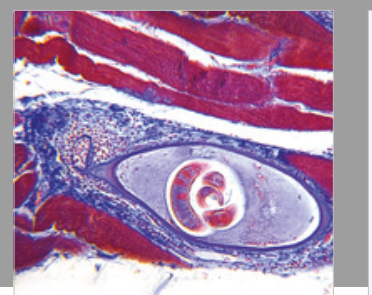

Gastroenterology Research and Practice

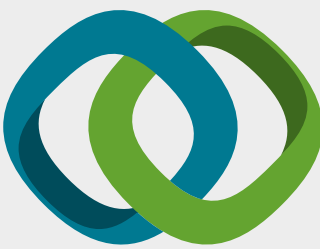

\section{Hindawi}

Submit your manuscripts at

www.hindawi.com
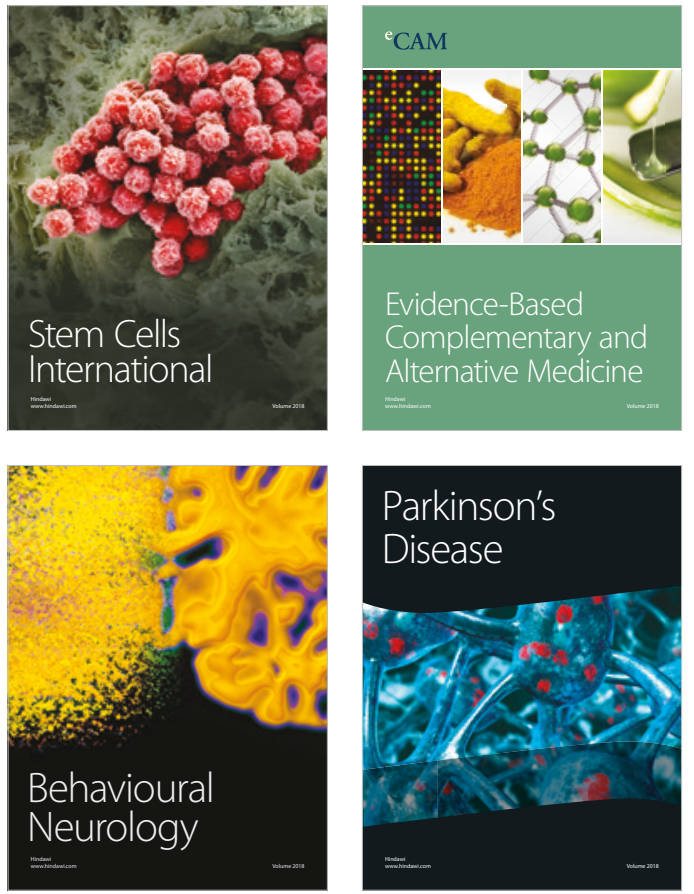

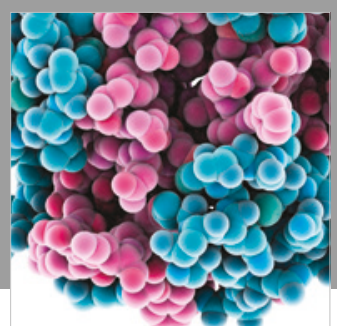

ournal of

Diabetes Research

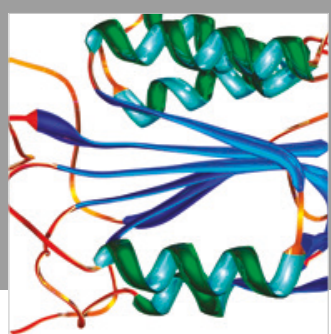

Disease Markers
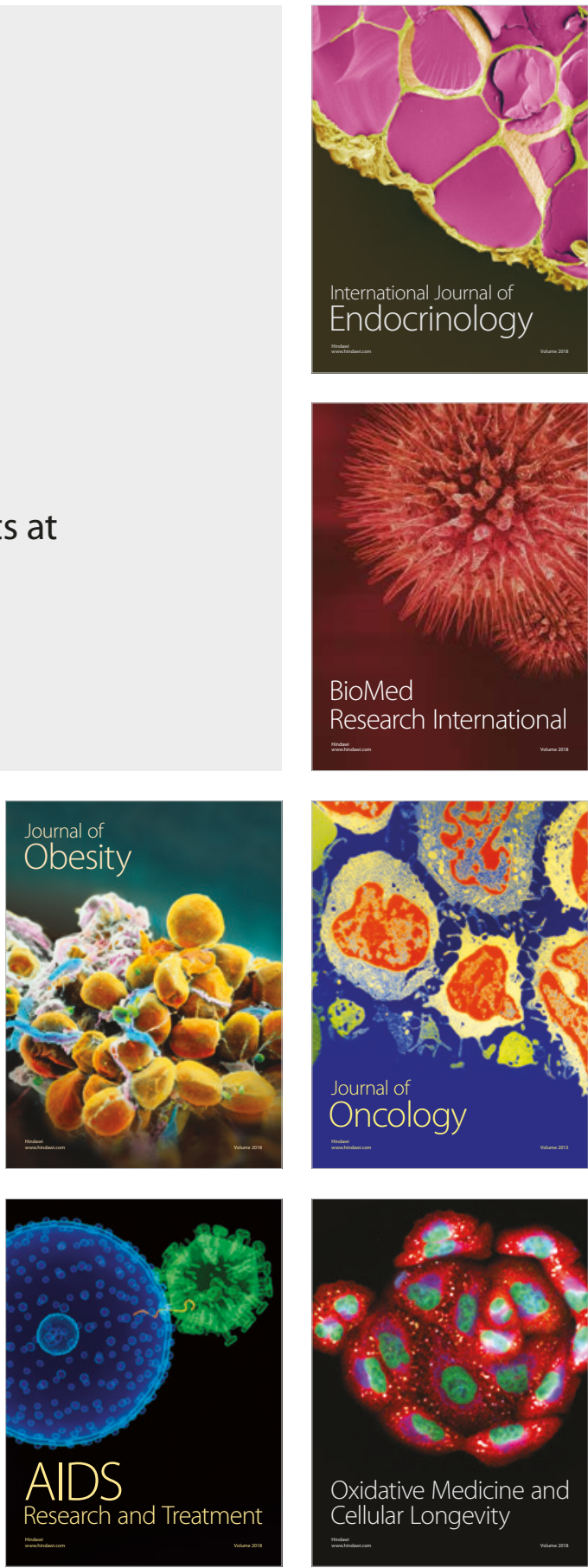